\title{
O VIDENTE AMÓS E A POLÍTICA: NEOASSÍRIOS E ARAMITAS NO QUADRO POLÍTICO DOS PROTESTOS EM ISRAEL NORTE NO SÉCULO VIII A.E.C.
}

The seer Amos and Politics: Neo-Assyrians and Aramaeans in the Political Framework of the Protests in Northern Israel in the 8th Century B.C.E.

João Batista Ribeiro Santos *

RESUMO: A questão da origem camponesa de Amós tem situado o debate acerca da sua atuação em torno das explorações econômicas pelas elites governantes, deixando pouco abordadas no seu livro as disputas de autoridades institucionais do antigo Israel. No contexto histórico interno, encontram-se a abertura das fronteiras e a fluidez das identidades resultantes das relações diplomáticas israelitas iniciadas no século IX no período da dinastia omrida. Por um lado, isso levou ao desenvolvimento econômico em Samaria, a capital; por outro, resultou no empobrecimento de grupos sociais produtivos do setor rural, por causa da alta tributação da terra e da produção. No contexto regional, o início do processo de provincialização no sul do Levante operado pelo império neoassírio somou-se aos conflitos de fronteiras entre Israel Norte ("Reino do Norte") e Aram-Damasco, o que refletiu na economia e agravou a crise política israelita. Em perspectiva, o corpus profético projeta uma visão de mundo política: as decisões do rei devem contemplar os benefícios aos pequenos produtores e comerciantes excluídos das grandes rotas comerciais. Metodologicamente, realizaremos uma operação historiográfica comparativa, porque analisaremos fontes bíblicas e extra-bíblicas contemporâneas às representações literárias proféticas do Livro de Amós. Nossa pesquisa pretende concluir que a atuação de Amós e o que ele representa historicamente se encontram vinculados inicialmente a essa conjuntura político-econômica internacional.

PALAVRAS-CHAVE: Profeta Amós. Antigo Israel. Assíria. História política. Memória cultural.

* Universidade Metodista de São Paulo, São Bernardo do Campo, São Paulo, Brasil. 
ABSTRACT: The question of Amos' peasant origin has shaped the debate about his role in economic exploitation by the ruling elites, leaving the disputes of institutional authorities in ancient Israel barely discussed in his book. The internal historical context shows the opening of borders and the fluidity of identities resulting from the Israeli diplomatic relations that began in the 9th century in the period of the Omride dynasty. On the one hand, this led to economic development in Samaria, the capital; on the other hand, it resulted in the impoverishment of productive social groups in the rural sector due to the high taxation of land and production. In the regional context, the beginning of the provincialization process in the south of the Levant, operated by the Neo-Assyrian empire, added to the border conflicts between North Israel ("Northern Kingdom") and Aram-Damascus, which reflected in the economy and aggravated the Israeli political crisis. Put into perspective, the prophetic corpus projects a political worldview: the king's decisions must contemplate the benefits to small producers and traders excluded from the large trade routes. Methodologically, we will carry out a comparative historiographical study, as we will analyze biblical and extra-biblical sources contemporary to the prophetic literary representations of the Book of Amos. Our study intends to conclude that Amos' performance and what he represents historically are initially linked to this international political-economic situation.

KEYWORDS: Prophet Amos. Ancient Israel. Assyria. Political History. Cultural Memory.

\section{Introdução}

A s pesquisas do rolo ou livro de Amós por muitas décadas aperfeiçoaAram uma metodologia que comtemplou o gosto pela profecia em favor dos pobres e de condenação para as elites governantes israelitas, enquanto oráculos de denúncia contra as opressões inumeráveis projetados inclusive para o tempo presente. Tem-se visto pouca variação temática, em parte pela impossibilidade de reconstruir o fato puro pela lonjura histórica. Então, o gosto em favor do pobre tornou-se gosto pelo clássico e pelo herói. Diante disso, pesquisar a atuação do assim designado vidente Amós (ḩzh 'Āmōs) e os enunciados do rolo intitulado com referência a ele torna-se desafiador quando nas buscas históricas se descansa o anverso para lidar com o verso, buscar o anti-herói, desfrutar de um gosto estranho: escavar os contextos das prioridades pessoais e representativamente coletivas de um proprietário de uma fazenda de gado miúdo e um campo de produção de frutos que esmaga seus desiguais citadinos.

Nada suprime o fato de existirem muitos motivos para os protestos internos

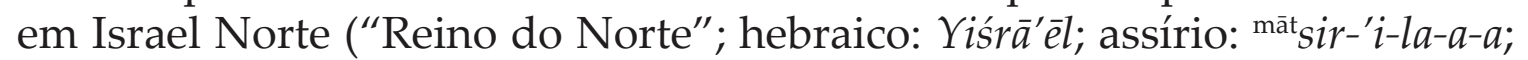
$y s r y \cdot r / l)$ : o desenvolvimento econômico, as grandes construções, importações e exportações de produtos de luxo destinam compensações injustas aos produtores por meio do forte aparato de taxação e perda de mercado 
dos pequenos produtores e comerciantes. Por outro lado, a estabilidade política e as realizações do reinado de Jeroboam II (783-743; Yārob'ām $)^{1}$ têm sido destacadas pelas pesquisas arqueológicas.

Com efeito, a declaração de liberdade de atuação, por não ser filiado a uma guilda profética, pouco ajuda quanto à atividade do agente social porque é redacional, é uma glosa que confirma que para ser profeta não se exige nenhum conhecimento técnico, mas certamente não se refere à linhagem de parentesco e talvez nem se refira à pertença comunitária. Resta-nos, para além da voz que se quis em favor do pobre, o quadro político com a pauta da economia. Esta proposta será desenvolvida abordando o quadro político, os testemunhos da materialização de neoassírios e aramitas no norte do antigo Israel e os contextos históricos dos protestos de Amós.

\section{0 quadro político regional}

As guarnições do império neoassírio, noreinado de Adad-narari III (810-783, Adad-nārāar $)^{2}$, após controlar o território do reino unificado de AramDamasco, avançam para o Israel Norte, outro reino levantino. A posição política israelita é conhecida pelos neoassírios como "casa de Omri" ( $\mathrm{m} h u$ -um-ri-i), assim como a liderança exercida no sul do Levante pela dinastia omrida no século IX, a construção da nova capital de Samaria (hebraico: Šōmarôn; assírio: Sāmirīna), a instrumentalização das guarnições de defesa e o desenvolvimento econômico.

No século VIII, os agentes sociais mudam de perspectiva política e a proporcionalidade da presença neoassíria aumenta; com ela, agravam-se os problemas econômicos de reinos como Israel pelas restrições de acesso e consequente maior taxação da produção local. Porém, nessa época, Israel encontra-se em plena recuperação das perdas territoriais para Moab e Aram-Damasco e expande seus domínios ao vale do Líbano, além de implementar grandes construções. À frente desses empreendimentos estatais está o rei Jeroboam II que, segundo Israel Finkelstein (2016, p. 28), controla o planalto de Gilead (Gil'âd), um distrito administrativo israelita em algumas décadas do século VIII.

\footnotetext{
${ }^{1}$ Utilizaremos nesta pesquisa a forma transliterada aproximativa ao hebraico para o nome de pessoas e lugares. Por ex., ao invés de "Jeroboão", grafamos "Jeroboam"; em relação ao Karmel, nome tanto da região da costa do Levante quanto do monte, por iniciar pela letra hebraica correspondente ao " $k$ ", por não adotarmos a forma aportuguesada " $c$ ", i.é, "Karmel" (har karmel, cf. 1Reis 18.19 etc.).

${ }^{2}$ Todas as datações desta pesquisa se referem a antes da assim chamada Era Comum, e consultamos as obras de dois pesquisadores: Liverani (2008) e Mieroop (2020).
} 
Em princípio contrastante, no período de domínio do mundo ou imperial, iniciado no ano de 744, a Assíria (Aššur; daš-šur) começa a retomar o papel de liderança no antigo Oriente-Próximo, interrompido por rebeliões internas que emergiram no ano de 827, por meio de novas campanhas anuais, quando já não exercia tanto impacto na bacia do Mediterrâneo e, por extensão, no Levante. Pelo contexto do período, Marc van de Mieroop (2020, p. 323) chega a afirmar que Urartu estende seus domínios sobre o norte da Síria por demonstração de fraqueza dos líderes militares da potência mesopotâmia, no início do século VIII, e a instabilidade gerada pelas rebeliões entre os anos de 762 e 759 contra o poder real. De certo modo, o fortalecimento das medidas de defesa proporcionado pelo desenvolvimento tecnológico na utilização do ferro, mas também pelos grandes limites das cidades, levaram muitos reis a organizarem a resistência ao pagamento de tributos.

Nos contextos que precediam, e de certa forma anunciavam, o estabelecimento do estado de vassalo do reino de Aram-Damasco em 738 e da província de Damasco (assírio: Ša-imērī̌šu) em 732, do estado de vassalagem do reino de Israel em 738 e a imposição de Estado títere a Samaria em 732 (fig. 1), o desenvolvimento estrutural operado pela elite governante e ricos proprietários israelitas certamente suscita protestos. Evidentemente, protestos não apenas da população produtora do setor rural, mas também do consumidor citadino, sabendo-se que ao sistema tributário acompanha o latifundismo. Assim, numerosas famílias perdem suas pequenas propriedades, resultando em empobrecimento e migração generalizados; mas a consequente escassez de alimentos não é a responsável direta pelo encarecimento de produtos. No quadro da campanha do rei Tiglat-pileser III (744-727, acádio: Tukultī-apil-Ešarra) ${ }^{3}$, no ano de 732, numa época de avanço do reino unificado de Aram-Damasco para o vale do Jordão visando dominar Israel e Edom, o vidente Amós flagra o modo de vida luxuosa das elites dirigentes política e economicamente, denunciando várias práticas: escravidão dos escasseados - seja para a exploração da mão de obra produtiva, seja para a violência sexual -, tráfico de gente, a falência do sistema jurídico, os usos ideológicos do culto sacrificial ao deus Yahweh (Yhwh) e a falsificação dos instrumentos de medição comercial.

\footnotetext{
${ }^{3}$ A memória coletiva de Amós 6.2 reflete a impressão causada pela ação militar nos limites de Israel Norte ("Reino do Norte") pelo império neoassírio no reinado de Tiglat-pileser III. Esse contexto de guerra modificará fortemente a sociedade israelita, como ficará comprovado na pesquisa. As traduções e transliterações de palavras do alfabeto acádio e de textos da Bíblia hebraica foram realizadas pelo autor; como informação bibliográfica acerca das citações bíblicas, cf. Elliger e Rudolph (1997). As citações bíblicas serão registradas, sempre que possível, em nota como chamada de fonte a conferir, evitando assim a frequente interrupção da leitura.
} 


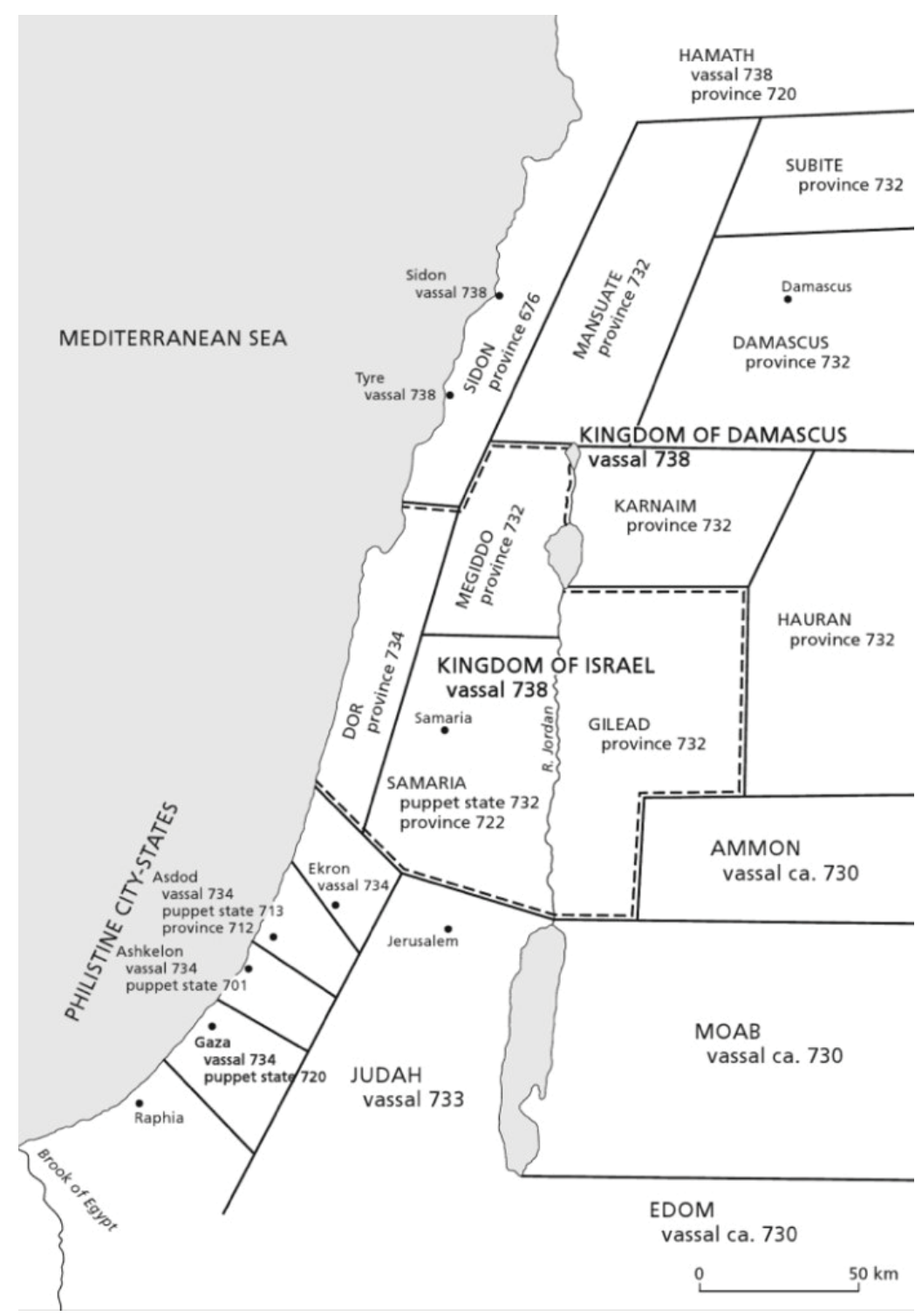

Figura 1. Mapa da anexação assíria dos Estados semíticos ocidentais no século VIII (MIEROOP, 2020, p. 326, versão inglesa do mapa).

A questão no rolo de Amós a ser abordada, portanto, é político-econômica, não podendo ser reduzida ao campo religioso nem, muito menos, às práticas cúlticas cotidianas dos ambientes domésticos ou palaciais ("palacianos"). Talvez seja por isso que Erhard Blum (2016) proponha ler algumas camadas literárias deuteronomísticas dos livros dos Reis ${ }^{4}$ considerando informações do conjunto de oráculos de Amós ${ }^{5}$ sobre as nações, utilizando-as como fontes para a busca de evidências das relações entre israelitas e aramitas. Têm-se em vista os ininterruptos conflitos por demarcações de limites territoriais entre vizinhos na região e a enunciação ex e ventu tanto do historiógrafo quanto das memórias proféticas.

\footnotetext{
${ }^{4}$ Principalmente 2Reis 9-10; mas também 2Reis 8.28-29; 13; 15; etc.

${ }^{5}$ Cf., por ex., Amós 1.3-4.
} 
Os limites israelitas, do noroeste da Síria ao sul do Mediterrâneo, informados pela Bíblia hebraica, ainda carecem de confirmação (2Reis 14.25, 28), mas dimensionam o seu poderio frente aos vizinhos em que são incluídos dois importantes pequenos reinos recentemente unificados, a saber, Aram-Damasco e Hamat-Luhuti (Hamati e Luhuti [aramaico: L'šs Lu'aš]), e os domínios filisteus. Assim como Blum (2016, p. 50-51), vemos claro exagero elogioso; a nosso ver, estranhamente mantido numa redação sacerdotal, ainda que refletido sobre a profecia com sinais de lamento proferida contra Jeroboam II na qual Hamat será devolvida aos aramitas (Amós 6.13-14).

No entanto, Blum (2016, p. 51) considera a possibilidade da presença política de Israel na região do Sinai baseado nas descobertas de Kuntillet 'A $\breve{g} \mathrm{r} u \mathrm{~d}$ (Horvat Teman), quando, na verdade, é preciso relativizar esse controle por tratar-se de um entroncamento comercial inter-regional onde podemos contar antigas cidades e assentamentos de filisteus imigrados na Idade do Bronze Tardio e de edomitas e aramitas, desde a segunda metade do século IX. Isso em nada nos impede de assentir que Jeroboam II é o maior governante do sul do Levante no século VIII num quadro político complexo, plurirreligioso ${ }^{6}$, multicultural e com afiliações políticas, mas distinguível etnicamente, ao menos no caso dos israelitas.

Nesse sentido, a conceituação cultural, em que envolve variadas tradições, oriundas da translabilidade ${ }^{7}$ de autoctonias móveis semíticas, tendia a ser rejeitada numa estrutura monárquica baseada na linhagem de consanguinidade como a israelita. Enquanto a elite governante integra-se numa rede de contatos políticos e comerciais, com testemunho arqueológico inclusive na Anatólia, as lideranças rurais conseguem apoios locais e urbanos, na tentativa de manter a visão de mundo dos clãs tribais. No século IX, Jehu

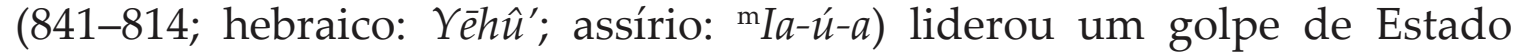
contra a terceira geração da dinastia omrida com o apoio de ruralistas arrebanhados por Jonadab, filho de Rekab (Yahônādāb, ben-Rēkēab) (2Reis 9-10), e, no século VIII, o representante desses clãs parece ser Amós ${ }^{8}$.

\footnotetext{
${ }^{6}$ Tal complexidade pode ser notada quando os escribas ou historiógrafos israelitas relacionam entre as cidades de Israel Norte ("Reino do Norte") algumas cidades que à época são sírias (cf. 2Reis 15). Podemos aludir ainda sobre a ausência de informação quanto ao que se refere às incursões de Tiglat-pileser III longe das grandes cidades, i.é, nas bordas e no setor rural, essas invasões podem ter atingido diretamente a população de agricultores e pastoralistas da qual Amós faz parte.

${ }^{7}$ Os termos "translabilidade" e "translação" são utilizados nas pesquisas sobre o desenvolvimento e trocas culturais no campo religioso (veja p.ex., SANTOS, 2018; cf. SMITH, Mark S. Gods in translation: deities in cross-cultural discourse in the biblical world. Grand Rapids, MI: Eerdmans, 2010; FLYNN, Shawn W. A story of YHWH: cultural translation and subversive reception in Israelite history. London: Routledge, 2020).

${ }^{8}$ Veja a autoidentificação do "vidente" como criador de gado e fruticultor (vaqueiro: bōqēr; figueiras: šiqmīm; gado de pequeno porte: ș'ōn) em Amós 7.14bb, 15a.
} 
Aparentemente muito respeitado pelo que evidencia o seu acesso às instituições monárquicas, o debate do vidente com o representante do rei na cidade de Betel (Bêt-'él) e sacerdote do templo real causou impacto: fora enviado para o palácio real de Samaria um relatório com as palavras do vidente (Amós 7.10).

Provocativamente, Nili Wazana postula que, ao "afirmar sua reivindicação de independência profética, Amós provavelmente não está diretamente na folha de pagamento do rei ou do templo, mas é razoável supor que o ato de profetizar no terreno do templo exigiu a autorização do estabelecimento" (2020, p. 216). Das linhas do conflito, nada indica estranheza em relação a Amós quanto aos procedimentos de entidades políticas, pois elas eram constituídas por alianças construídas entre líderes de clãs das cidades, aldeias e tribos. Por outro lado, a novidade entre Aram-Damasco e Israel consiste no fato de serem dois vizinhos com linguagens da mesma origem matricial, portanto, com algum traço etnológico conquanto seja verificável a designação do patriarca Jacob ( Ya ăqōb) como aramita foragido ${ }^{9}$, e de manterem a rivalidade acima das ameaças neoassírias em razão de memórias antigas das violências praticadas pelo rei Hazael (assírio: ' $h a-z a-a$ ou haza-il) na expansão aramita por terras israelitas.

\section{Materialização histórica de neoassírios e aramitas em Israel Norte}

Os contatos entre Damasco e Israel, como entidades estatais, ocorrem desde cerca de 970, segundo as inscrições reais do império neoassírio que colocam aquela cidade-Estado síria no mapa de expansão imperial, mas também em antigas redações historiográficas dos livros dos Reis e Samuel, na Bíblia hebraica ${ }^{10}$. Nesses mais de dois séculos, foram raros os acordos regionais nos quais os mais fortes reinos do sul do Levante combateram unidos contra um inimigo comum. A breve coalizão em 853 na guerra de Qarqar (Karḳar) contra Shalmanesar III (858-824; assírio: Šulmānu-ašaridu) foi rompida pela instabilidade política em Damasco com o assassinato de

\footnotetext{
${ }^{9}$ Sobre Jacob, de família aramita por linhagem de parentesco, cf. Gênesis 31.20, 24; para Jacob como aramita por local geográfico, cf. o enunciado pós-exílico de Deuteronômio 26.5ba: 'ărammî̀ 'ōbēe 'ābî ("aramita foragido era meu pai"). Além disso, a redação do rolo de Amós (Amós 1.1) propõe uma chave historiográfica ao mencionar no cabeçalho o terremoto que teria acontecido entre 780 e 750 .

${ }^{10}$ Acerca da presença tanto de Damasco quanto de Israel Norte em inscrições monumentais neoassírias cf. Santos (2018; 2021, pesquisa atualmente sendo editada para publicação); cf. também Matthews (2019, p. 17) e Mieroop (2020, p. 293-96, 316).
} 
Hadad-'ezer (Adad-'idrī) praticado por Hazael no ano de 844, esse militar coroado rei unificou Aram-Damasco. Outro fato que contribuiu para com a individuação das políticas locais foi a tomada de poder por Jehu, em Samaria, em 841.

Sobre essas crises, as fontes atestam uma disputa de narrativas entre israelitas e aramitas acerca dos extermínios perpetrados em Ramot Gilead (Rāmōt Gila'âd), no médio Jordão, e em Samaria (SANTOS, 2018; 2019b). Com efeito, a geografia física dos dois reinos por vezes se confunde pelas possessões que ultrapassam fronteiras de regulações mentais entre pequenas cidades não muradas. André Lemaire (2019) aborda as divergências e referências da emergência do reino da antiga cidade-Estado de Damasco, repletas de etapas territoriais, pelas quais entendemos que os processos da mobilidade territorial ocorridos na Idade do Ferro I-II são, na verdade, inapreensíveis completamente.

Posto que temos por finalidade apresentar registros históricos, os conflitos tendem a arbitrar os fundamentos historiográficos das fontes. Por isso será preciso assinalar que as posições geográficas de Israel, seu crescente poderio, fornecem motivação para uma guerra com Damasco, ou reino de Gesur (et-Tell Gešur), por volta do ano $900^{11}$. As invasões de cidades do alto Jordão, Dan (Dān), Hazor (hebraico: Hāsșōr) e outras, ainda não estão totalmente esclarecidas pela pesquisa arqueológica, fatos considerados por Lemaire $(2019$, p. 251) como difíceis de ser interpretados no conjunto das destruições causadas pelas guarnições sírias.

A situação política dos israelitas muda com a ascensão ao trono de Omri ('Omrî, c. 881-874), cuja dinastia ficou ente os anos de 881 a 841 . No período de reinado de Omri a Ahab (c. 874 - 853; hebraico: ' $A$ h'a $a \bar{b}$; assírio: $\left.{ }^{\mathrm{m}} a-h a-a b\right)$ (874-853), Israel recuperou as cidades perdidas para populações sírias e terras nas bordas com intervenções militares na Transjordânia, a leste, e nas estepes sírias, a noroeste ${ }^{12}$. Situando-nos no período de atividade de Amós, o início de reinado de Jeroboam II encontra o reino de Aram-Damasco em condição estrutural superior, empreendendo sucessivos assédios a Samaria (2Reis 6.24-7.20), além das intervenções neoassírias iniciadas na região pelo rei Adad-narari III.

\footnotetext{
${ }^{11}$ Mesmo aqui continuamos em hipóteses diante das camadas redacionais hebraicas e das possibilidades de testemunhos arqueológicos; sobre isto, André Lemaire guia-se pela Bíblia hebraica e diverge de Angelika Berlejung (LEMAIRE, 2019, p. 250-51).

${ }^{12}$ A relação bibliográfica é longa para a pesquisa desses acontecimentos, sugerimos duas recentes pesquisas de Santos (2019a; 2019b).
} 


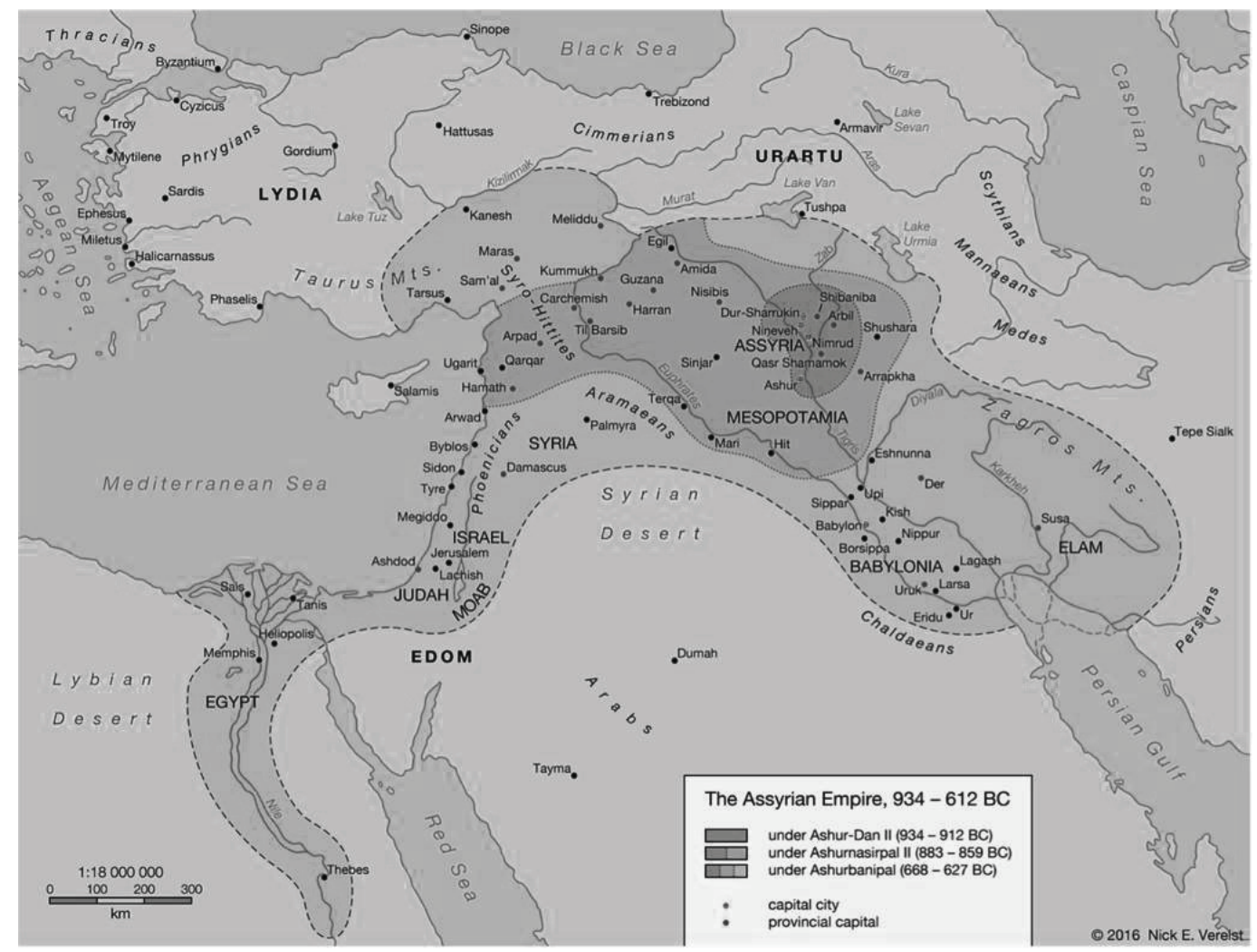

Figura 2. Mapa do império neoassírio ${ }^{13}$

Pensando em uma tentativa de promover uma reconciliação entre os países vizinhos ou eliminar qualquer escala de poder, como ocorre a Angelika Berlejung (2016, p. 371), os redatores pós-exílicos do rolo de Amós teriam organizado paralelos do enunciado de Amós 9.7 com o livro do Gênesis para estabelecer uma conexão com o êxodo dos "israelitas" do Egito e retorno dos aramitas de Qîr. O retorno a Damasco teria ocorrido em meio aos cercos neoassírios do ano de 773. Em ambas as fugas, o deus Yahweh aparece como agente libertador. Com isso, a tradição profética representada por Amós inclui os aramitas não apenas no "mito de continuidade", como alude Berlejung, mas, muito mais importante, no mito de fundação do antigo Israel e do culto a Yahweh.

Não tomando o termo "aramita"/“arameu" por significância pejorativa diante da "aramaicização" da província da Samaria no período Persa Aquemênida, os redatores sacerdotais da colônia persa de Yehud transmitem a ideia de que a crise em Israel foi causada pelas elites governantes. Por outros termos, os conflitos militares externos são ignorados na avaliação posterior para possibilitar maior pertinência traditiva tanto das sagas dos patriarcas quanto da origem comum e conflituosa entre israelitas e aramitas. De fato, não podendo eliminar o caráter coletivo por meio das

${ }^{13}$ Disponível em: DevianArt.com/undevicesimus. Acesso em: 10 fev. 2021. 
memórias do êxodo ${ }^{14}$, escolhe-se Yahweh como polo condutor dos dois pequenos reinos.

A integração, ainda que tardia, fazia sentido pelos cruzamentos étnicos materializados com a contribuição das culturas, mas acima de tudo porque os problemas que comprometem a sobrevivência dos israelitas são gerados pelas categorias dirigentes citadinas. Estão, portanto, no contexto dos símbolos do poder real sobre o trono. Quando a "paz" perde sentido como dom imaterial da existência, após o evento da ascensão ao trono, os bens mobiliários e decorativos passam a constituir-se em apresentação exterior do poder. Eis por que escapa às relações interpessoais a lógica das origens, e as sociedades passam a estabelecer o conflito como forma de definir a exclusão.

Tal postulação é assumida no domínio da profecia no oráculo contra AramDamasco em Amós 1.3-5: resultante da avaliação dos reis que formam um cinturão de resistência contra os assédios da Assíria, prognostica-se o extermínio de todos os aramitas, a começar pela queda de Damasco. Seguindo o mapeamento político de K. Lawson Younger (2016, p. 40-41, $318,366-71,640)$, compreendemos que o oráculo é claramente favorável à Assíria em benefício do comandante militar Shamshi-ilu (Šamšǐ-ilu), líder da invasão a Damasco no ano de 773. Não restará sequer a cidade de Bet Eden (bēt 'eden); identificada nas inscrições reais assírias do século IX como Til-Barsip (Tell Ahmar) ${ }^{15}$ e localizada a leste do rio Eufrates, essa cidade síria governada por Shamshi-ilu era uma província assíria na época de Amós ${ }^{16}$. O oráculo conclui-se prometendo enviar todos os povos envolvidos ('am-'ărām) de volta para Qîr, transformada em província assíria no ano de 732 pelo rei Tiglat-pileser III. Diante desse percurso, a morte como maledicência de Amós ao rei Jeroboam II e ao sacerdote Amaziah ${ }^{17}$ deve ser entendida nesse contexto.

Os palácios reais e grandes casas da aristocracia com seus mobiliários decorados com painéis de marfim; guarnições militares; a constituição do estafe real com músicos, artesãos e escribas eruditos; a manutenção de templo com sacerdotes e celebrações sacrificiais; os banquetes reais com bebidas e comidas finas; joias e vasos preciosos. Todo esse conjunto de bens e serviços faz parte do testemunho material das denúncias de Amós (Amós $3.15 ; 6.4-6$ ) porque tem o custo da espoliação tributária e

\footnotetext{
${ }^{14}$ Divergimos de Berlejung (2016, p. 371) por entender que Deuteronômio 26.5 opera a continuidade entre as origens israelitas e aramitas dentro da tradição maior, o êxodo; as glosas do rolo de Amós demonstram a adesão no período pós-exílico às antigas tradições.

${ }^{15}$ Bet Eden tem sido conectada indevidamente a Bìt Adīni.

${ }^{16} \mathrm{O}$ que permanece em debate é a identificação de Shamshi-ilu (Šamšīililu) em Amós 1.5c.

${ }^{17}$ A grafia busca uma transliteração aproximada com o nome hebraico do sacerdote, Amaziah ('Ămașayāh), cf. nota 1 e outras.
} 
esgotamento físico dos pequenos produtores e comerciantes da cidade e do setor rural. Ora, a crítica é justa!

Destarte, é razoável notar que os reis de Israel, assim como os reis de Aram-Damasco, seguem o estilo dos reis neoassírios em sua época. Os relevos de Asurnasirpal II (Aššurnașirpal) (883-859) e Senaquerib (704-681; assírio: ${ }^{\mathrm{md} E N . Z U-S ̌ E S . M E S ̌-e r i-b a ; ~ S i n n-a h h ̣ e-e r i ̄ b a), ~ a p e n a s ~ p a r a ~ f i c a r m o s ~ n o s ~}$ entornos temporais da atividade de Amós, ilustram esse modo de vida (LION; MICHEL, 2014a, p. 181; 2014b, p. 188-92). A crítica é econômica! As cidades são os ambientes geográficos das denúncias não apenas por manterem o endereçamento das instituições monárquicas, mas porque aí o contingente de pessoas em estado vivencial de miséria era crescente.

O que lança os enunciados do rolo de Amós para o plano religioso são as redações sacerdotais e pós-sacerdotais que, ao deslocarem os eventos do campo político para o campo religioso, eliminam qualquer dificuldade à inteligência cognitiva da leitora e do leitor quanto ao que diz respeito à história dos eventos, facilitando o seu projeto de potencializar o ponto de vista teológico da história. No caso do rolo, esse modelo escribal não deve ser abandonado porque ainda permite o acesso de registros elucidativos.

As celebrações cúlticas mencionadas têm realmente várias tradições; Jonathan Greer (2017, p. 12-13) nota que a adoção de culturas próprias de outros grupos populacionais não ocorre de forma acrítica, sendo que as histórias desempenham um papel polêmico nas camadas redacionais da Bíblia hebraica. Com efeito, as narrativas historiográficas e do gênero profético mantêm a ambiguidade de cultos a Yahweh e a outras divindades simultâneos nos séculos IX e VIII. Descobrimos reelaborações estéticas de Yahweh como o Deus da Tempestade no antigo Israel ${ }^{18} \mathrm{e}$, ainda que enuncie criticamente a veneração a Haddu em Dan (Amós 7.13; 8.14), justificadamente pela ausência de justiça em favor dos escasseados, os redatores do rolo de Amós deixam de mencionar, como notou Greer (2017, p. 13), a influência da cultura aramita no culto israelita.

\section{Protestos em favor do pequeno produtor}

A influência cultural aramita implícita nos enunciados compósitos do rolo profético pode ser compreendida por meio das transmissões operativas da religião. O deus Yahweh está perdendo espaços nos lugares de culto, e isso estranhamente supera em importância a perda de glebas de

\footnotetext{
${ }^{18}$ Assim, a elaboração estética influenciada pelas tradições de Aleppo e Ugarit do Salmo 29 e o panteão canaanita do Salmo 82 (cf. SANTOS, 2018).
} 
terra pelos novos assentamentos de migrantes da Síria e o alto preço dos produtos locais por causa das taxas tributárias. Estes dois problemas estruturais geram as fraudes no calendário religioso, que tem consequência na administração do trabalho social por abolir o descanso semanal, e no sistema de medidas comerciais.

O perspectivismo cultural israelita lança luz sobre o presentismo ${ }^{19}$ divino em ambientes de conflito num plano semelhante ao que se articula em relação aos agentes sociais. Encontramos no Mediterrâneo indicação de uma tradição israelita cristalizada quanto ao culto ao deus Baal $\left(B a^{\prime} a l\right)$. Referimo-nos ao espaço sagrado no monte $\mathrm{Karmel}^{20}$ pertencente ao deus Baal e ainda motivo de disputas entre diferentes grupos de israelitas ${ }^{21}$. A visão da perícope de Amós 9.1-6 transmite duas iconografias literárias. A primeira apresenta Yahweh como o Deus da Tempestade, um Haddu que mantém o seu controle sobre os altiplanos e convida as águas para as suas empreitadas (notemos não se menciona que a divindade tem exatamente controle sobre os poderes do mar, $Y \bar{a} m)^{22}$. No entanto, a divindade mantém consigo armas militares para liderar vitórias contra os seus inimigos. $\mathrm{Na}$ segunda iconografia, temos a terrível serpente marinha (nāhăšs), escravizada e, assim como o mar, a serviço de Yahweh.

Como notou Noga Ayali-Darshan (2020, p. 165), o mar continua a fazer parte do imaginário israelita como reino singular, onde a serpente reina. Tudo se passa sem relativizar a força das tradições mesopotâmias nas bordas do Levante, onde o controle dos céus, do submundo e do mar - "as fronteiras remotas do mundo habitado" da tradição sapiencial do antigo Oriente-Próximo (fig. 2) (AYALI-DARSHAN, 2020, p. 202) - sugere, por meio desses novos elementos, a construção sacerdotal de uma moldura dimensionada para a composição do quadro político em Israel.

Nesse mundo complexo, no dizer de Ayali-Darshan acerca de Amós 9.1-3, "Amós descreve como a perseguição de Yahweh pelos perversos se estende a todos os cantos do mundo" (2020, p. 202), passando uma mensagem na qual "os israelitas estavam familiarizados com a ideia de que a serpente marinha não foi morta, mas tornou-se ajudante de Yahweh já por volta do século VIII" (2020, p. 202). A nosso ver, como o mar continua sendo um reino incontrolado pelos israelitas, o monstro

\footnotetext{
${ }^{19}$ Fazemos uso de terminologia historiográfica da pesquisa realizada por François Hartog, em: Regimes de historicidade: presentismo e experiência do tempo. Belo Horizonte: Autêntica, 2014.

${ }^{20} \mathrm{O}$ nome tanto da região da costa do Levante quanto do monte inicia-se pela letra hebraica correspondente ao " $\mathrm{k}$ ", por não adotarmos a forma aportuguesada "c", i.é, "Karmel" (har karmel, cf. 1Reis 18.19 etc.); cf. n. 1 e outras.

${ }^{21}$ Recentemente publicamos uma pesquisa sobre o tema da disputa de espaço sagrado envolvendo israelitas de partidos religiosos divergentes (cf. SANTOS, 2017, p. 131-147).

${ }^{22}$ Cf. nota 23.
} 
marinho e o próprio mar são tomados como ajudantes de Yahweh, por isso as camadas literárias sacerdotais jerosolimitas insistem em reafirmar as conexões entre os elementos criados pela divindade (Amós 4.13; 9.6), destacando, porém, o estabelecimento da terra como único local de relações.

Afortunadamente, ficam claros, no que diz respeito ao comércio, os indícios de protestos contra os grandes empresários que utilizam as rotas da costa do Levante. Sabemos que, mesmo após o colapso ocorrido no início do século XII, os portos das cidades-Estado de Ugarit (atual Ras Shamra; escrita mais antiga: Ug-ga-ra-atki; acádio: KURú-ga-ri-it) e Biblos (Gu-ub-la; fenício: Gebal; grego: Býblos) continuaram a operar em pequena escala a comercialização e os preços das mercadorias na região. Ambas as cidades designaram o deus Baal como "rei da cidade" e maioral de um panteão em que Yamm, o Mar, foi controlado. De sua acrópole, o monte Șapānu (hebraico: Șāpôn), Baal iluminava o mar em benefício dos navegantes e mercadores ugaríticos. Yamm, que não pode ser designado como deus pelos israelitas, é agora a serpente parceira do deus Yahweh!

Em territórios de populações migrantes, onde as novas culturas cruzam com antigas tradições, os costumes de ambientes domésticos passam a representar o caráter identitário. No caso de Israel, as numerosas tradições de espaços sagrados e necessidade de variados poderes para as empreitadas da vida nas bordas levam a composições inusitadas acerca da origem e, sobretudo, da presença divina.

Na parte superior da moldura textual do rolo de Amós, antecedida pelo cabeçalho, o escriba, à maneira de intérprete sacerdotal, situa-se bem em Jerusalém para encetar a profecia. Mas nada lhe abstrai a finalidade de dirigir-se ao povo do norte, ao monte Karmel e seu santuário dedicado a Baal, com o alarme da destruição iminente que consistirá na "turbulência da natureza" provocada pela "aproximação de Yahweh" (Amós 1.2). Está em uso uma criação estilística israelita adotada pelos escribas jerosolimitas não apenas no rolo de Amós. Henrik Pfeiffer afirma que "embora existam vários paralelos histórico-traditivos do antigo Oriente-Próximo para o elemento 'turbulência da natureza', a abordagem da divindade permanece exclusiva para o antigo Israel" (2017, p. 122). Ocorre interação cultural por parte dos agentes sociais envolvidos, motivada por apropriação de tradição de lugar. Com as ameaças de punição, tenta-se marcar as distinções daqueles pequenos

\footnotetext{
${ }^{23}$ Notemos que os pequenos reinos e cidades-Estado relacionados no capítulo 1 do rolo de Amós têm origem semítica comum no sul do Levante - no Mediterrâneo, na Transjordânia e nos vales e altiplanos vizinhos ao rio Jordão - e os contatos externos fazem parte da mobilidade social praticada na região. Para uma pesquisa sobre a origem das tradições em torno de Yahweh tendo como fonte de tradição a Bíblia hebraica e descobertas arqueológicas, cf. a importante pesquisa de Henrik Pfeiffer (2017, p. 115-144).
} 
reinos e cidades-Estado ${ }^{23}$, mas a tentativa fica comprometida pela função justificadora da própria redação dos oráculos de desgraça - isso por si só já requer conhecimento entre as partes.

Traditadas em Israel são também as formas de manifestação profética, típicas do antigo Oriente-Próximo, em que o vidente de Yahweh afirma ter consigo o conhecimento prévio do que será executado pela divindade, a fim de justificar uma requerida veridicidade da desgraça comunicada (Amós 3.7; 7.1-9; 8.1-3; 9.1-4). A diferença qualitativa do líder, expressamente indicada por meio da possessão divina, faz sentido diante de conflitos, como o vivido por Amós em face a Amaziah, representante do rei na cidade de Betel e sacerdote do templo real.

Amós é um antagonista de Amaziah em representações sociais, suas diferenças verbais não devem ser classificadas nem como "conflito profético" nem como "disputa de narrativa" como defendido por vários pesquisadores (cf. WAZANA, 2020, p. 210). Há, sim, um pressuposto quanto à questão de autoridade estabelecida pelo reino, ou seja, debate-se a legitimação junto à audiência pública; como o protesto extrapola lugares comuns do profetismo, fica exposto o papel do profeta. Acima aludimos à maledicência de Amós contra Amaziah situando-a no contexto da presença neoassíria; sim, mas cabem agora os desdobramentos do ponto de vista dos redatores. O sacerdote não é contra a prática profética, muito menos desmente a denúncia; o que ele deseja é silenciar a estranha liderança oposicionista que fala livremente "no meio da casa de Israel", baqereb bêt Yiśrā'ēl (7.10bb). Fato contínuo, Amós é expulso do reino: "foge para a terra de Judah e come lá pão e lá profetiza" (7.12bb).

Visando esmagar o sacerdote num discurso de controvérsias, o enunciado retórico anuncia a queda do sacerdote, uma vez que o representante palacial $^{24}$ que confronta o profeta, como observou Wazana (2020, p. 212), recebe a pecha de "falso profeta" e por isso deve morrer. Em seguida inscreve-se a destinação da família do sacerdote, particularmente da mulher dele, sentenciada à prostituição na cidade ${ }^{25}$. Por oposição de atividade, o sacerdote "santo" terá uma mulher "contaminada" (Levítico 21.7). Tudo isso faz parte da disputa de lugar de prestígio. Amós reage ao banimento para o exílio; na verdade, não é para o exílio posto que ele é realmente de Judah (hebraico: Yahûdāh; assírio: $\left.{ }^{k u r} I a-\hat{u}-d a-a-a\right)^{26}$. Nisto

\footnotetext{
${ }^{24}$ Outra expressão, mais comum: "palaciano".

${ }^{25}$ Essa infeliz alusão à mulher por si só é duvidosa, senão característica de partido sacerdotal que transfere para a figura feminina as desgraças do campo religioso. Acerca de iconografia literária da mulher na Bíblia hebraica, veja Santos (2019c, p. 257-74).

${ }^{26}$ Assim como a palavra "karmel", referida ao monte, o nome do sacerdote, Amaziah ('Ámașayāh), usamos do mesmo modo a transliteração do hebraico para o assim chamado Reino do Sul: Yəhûdāh, ou Judah, ao invés da forma aportuguesada "Judá"; cf. nota 1 e outras.
} 
temos outra linguagem retórica em síntese de divergência de localidade, uma síntese de diferença que, se não for étnica, é ao menos de caráter administrativo entre um reino e outro. Contudo, a humilhação consiste no fato de um homem de posses e de espírito livre ser enviado a profetizar por migalhas de pão.

Foi necessário escavarmos aspectos complementares para descobrir também que havia uma tentativa de deslocamento do debate político por meio de minucioso trabalho redacional. Parece-nos que Stephen C. Russell alcança a intenção escribal:

Duas das mais famosas representações bíblicas de Betel são encontradas em Amós 7.9-17 e 1Reis 12.25-33. Amós 7.9-17 relata um confronto entre Amaziah, o sacerdote de Betel, e o profeta Amós. De acordo com 1Reis 12.25-33, Jeroboam, rei de Israel, ergueu uma imagem de um bezerro em Betel e estabeleceu um sacerdócio lá. Ambos os textos imaginam Betel como um santuário sob a jurisdição dos reis de Israel, com um sacerdócio que tinha uma relação especial com a monarquia israelita. Os textos, no entanto, são comprovadamente das mãos de escribas judaítas, que parecem ter assumido que a relação de Betel com a monarquia israelita era exatamente como a relação do Templo de Jerusalém com a monarquia judaíta. (RUSSELL, 2016, p. 365, tradução nossa)

Poderemos apreciar a ironia da transferência de sentido! Porém, mesmo que fique preservada a identidade coletiva tribal representada por Betel, a intenção escribal desloca os contextos israelitas para o juízo de centralização de Jerusalém enquanto exalta a sua monarquia ainda em atividade, situando como periféricos de Jerusalém a cidade de Betel e seu santuário real. Com isso, os escribas realizaram a tarefa de nomear os locais de culto e divindades estanhas ao panteão ${ }^{27}$. Durante a operação redacional visou-se a compreensão em contexto religioso tanto dos protestos acerca das tomadas de decisão do rei que atingem os pequenos produtores e comerciantes, seja da cidade, seja do setor rural, quanto da reivindicação da propriedade da terra pelas populações autóctones.

Literariamente síncrona, fora elaborada uma decisão insólita ex êventū de dizimar com a população israelita (Amós 5.2; 8.2), posto que a desqualificação dos santuários ao ar livre, templos e práticas cúlticas são enunciadas sem, no entanto, oferecer um lugar alternativo. Ou seja, a proposição de mudança para o roteiro de destruição, "exigi o bem e não o mal" (Amós 5.14aa), é por demais abstrata. Martti Nissinen (2017, p. 250-56) inquiriu questões como estas no rolo de Amós quando pesquisou a crítica ao culto pelos profetas. Caso a transmissão tenha por finalidade oferecer respos-

${ }^{27} \mathrm{Na}$ relação constam locais com complexos cúlticos como Betel (Amós 3.14; 4.4; 5.5; 7.13), Gilgal (Amós 4.4; 5.5), Beersheba (Amós 5.5; 8.14), Samaria (Amós 8.14) e Dan (Amós 8.14), lugares para cultos ao ar livre como "os lugares altos de Isaque" e os "santuários de Israel" (7.9). Com os espaços sagrados, aparecem as divindades astrais Sikkūt e Kiyyūn (Amós 5.26). 
tas acerca da destruição de Israel e esperançar, enfim, um "reino unido" almejado pelo rei Josias no século VII, a recepção do rolo na colônia de Yehud $^{28}$ obteve êxito.

No entanto, retomando a delimitação e os contextos do século VIII, as polêmicas teológicas não sobrepõem as posições geográficas de AramDamasco $^{29}$, assim como o avanço sistemático das guarnições neoassírias que seguem destruindo muitas cidades nos limites israelitas e imposto seus tratados de vassalagem. O jovem Amós deve ter testemunhado um acordo fronteiriço entre os dois reinos, no qual ficaram estabelecidos os limites entre ambos na embocadura do Jordão, sendo posteriormente rompido porque Jeroboam II avançou do Jordão em Lo-Dabar $\left(L \bar{o}^{\prime} D \bar{a} b \bar{a} r\right)$ a Qarnayim (Qarnāyim) (Amós 6.13), no sul da Síria, de Dan ao noroeste sírio na cidade de Hamat, mas de forma emblemática a reconquista da jordaniana Gilead, conquistada por Tiglat-pileser III vinte anos depois ${ }^{30}$.

As tensões são demasiadamente indicativas dos regulamentos do exercício da autoridade no antigo Oriente-Próximo, onde virtudes de governantes são glorificadas e protestos e problemas internos por vezes são omitidos nas inscrições reais. A Bíblia hebraica torna-se uma exceção por inumeráveis denúncias, superando a presença de representantes reais nas decisões comunitárias juntamente com os anciãos. Não obstante, inscrições mesopotâmias, biografias tumulares egípcias e camadas literárias bíblicas preservaram atos de caridade de reis, como o cancelamento de dívidas, é o que nos lembra John F. Robertson (2007, p. 222); insuficientes, no entanto, para reparar as perdas causadas pelas guerras e pelo sistema tributário. As denúncias dos sofrimentos dos escasseados no antigo Israel ${ }^{31}$ refletem em escritos sapienciais tarefas sociais abandonadas pelos reis que decretam leis injustas; nesse caso, a justiça social teria ficado preservada no conjunto dos valores familiais de escribas que, por vezes, demonstram alguma relação com comunidades marginalizadas.

Essas leis injustas, nos contextos por nós apresentados, estão na dinâmica do sistema absolutista. Robertson insere Amós na sua pesquisa da história

\footnotetext{
${ }^{28}$ A transliteração do nome da província persa no assim chamado período pós-exílico, Yəhûd.

${ }^{29}$ Relatórios arqueológicos e pesquisas da história dos espaços sagrados citados nesta pesquisa têm confirmado a presença aramita nas grandes cidades israelitas.

${ }^{30}$ Em relação ao antigo Israel (Israel Norte e Judah) nas fontes assírias, escribas responsáveis pelas inscrições reais de Tiglat-pileser III chegam a atribuir nomes trocados a reis israelitas, talvez por falta de informação quanto às sucessões no trono. Por exemplo, Ahaz é mencionado como se fosse Jeoahaz, "Jeoahaz da terra de Judah", i.é, " Ia-ú-há-zi kurIa-ú-da-a-a (WEINGART, 2020, p. 285-86); isso aconteceu antes no Obelisco Negro do rei Shalmanesar III, onde Jehu é designado como "Jehu da casa de Omri", i.é, mia-ú-a DUMU mhu-um-ri-i (SANTOS, 2021, pesquisa atualmente sendo editada para publicação).

${ }^{31}$ No antigo Israel havia várias categorias de pessoas em estado de pobreza; para uma amostra lexicográfica (cf. SANTOS, 2009, p. 164-67).
} 
em que explana as tensões sociais num mundo determinado pelo império neoassírio:

A ascensão da Assíria foi o prenúncio de uma sequência de sistemas imperiais que introduziram novos elementos na dinâmica de governante versus governado. O saque, a destruição, a extermínio, o estupro, a mutilação e a escravidão que normalmente acompanhavam a conquista militar eram fatos sombrios da vida antiga desde os primeiros tempos registrados. Os sistemas imperiais do primeiro milênio A.E.C., entretanto, empregavam ainda outros meios de assegurar a dominação política e a exploração econômica esmagadoramente sistemática. (ROBERTSON, 2007, p. 223, tradução nossa)

Os documentos registram a evolução da instrumentalização monárquica destinada ao extermínio dos escasseados das bordas. Destarte, com razoabilidade, pode-se afirmar por fontes documentárias que o controle das rotas pela Assíria não significou empobrecimento no sul do Levante. A continuidade do transporte de objetos de luxo na região, oriundos da Fenícia e Anatólia, o atesta. Apesar de certo malogro administrativo deixado pelo reinado de Jehu e posteriormente a ele, registra-se no período de reinado do assírio Adad-narari III grande prosperidade econômica em Israel:

Ainda o relato da crescente prosperidade econômica descrita no Livro de Amós, juntamente com a evidência arqueológica da presença de mais bens de luxo durante o reinado de Jeroboam, é uma indicação adicional de que Israel entre 800-750 tem mão livre para expandir suas redes comerciais para a Transjordânia e para o porto de Elat, e não é forçado a defender continuamente suas bordas. (MATTHEWS, 2019, p. 147, tradução nossa)

Victor H. Matthews conecta ao enunciado de Amós 6.4-8 os testemunhos materiais extra-bíblicos. Não obstante, Matthews (2019, p. 148) afirma que a política de Jeroboam II foi caótica, como se ocorresse a falência das estruturas nacionais. Quanto a isto, divergimos por considerar que a tributação que causou o desabastecimento tem origem nos problemas causados pelos assédios por parte de Aram-Damasco e Assíria. Pesquisas arqueológicas têm demonstrado que as grandes construções atribuídas a Salomão na Bíblia hebraica, foram, na verdade, empreendidas no reinado de Jeroboam II (LIVERANI, 2008, p. 162-64). Para além disso, as pesquisas têm demonstrado o desenvolvimento nos altiplanos e fortificações na cidade de Dan, construções de grandes "estábulos" e estruturas "impressionantes" em Megiddo ${ }^{32}$, um sistema de fortificações em Hazor e sistema de torres e palácio em Gezer; muros monumentais em Joqneam (Yoqnə'ām), Samaria e Bet Shean (atual Tell el-Husn; Bêt Ša'ān) (KILLEBREW, 2014, p. 737-38). Citemos diretamente Ann E. Killebrew sobre a grandeza comercial e cultural israelita na época de Amós:

Dois conjuntos de artefatos - um grupo de marfins e uma coleção de ostraca originários de Samaria, capital do reino de Israel - fornecem informações valiosas sobre os sistemas culturais e econômicos da conquista pré-assírios.

${ }^{32}$ Nome hebraico, Magiddô, com a letra "d" duplicada e o "o" como holem-waw (cf. 2Reis 23.29 etc.). 
Os marfins de Samaria, compreendendo aproximadamente 1.000 fragmentos, personificam a prosperidade e o caráter cosmopolita de Israel durante este período e são mencionados nos oráculos de Amós no século VIII (ver por exemplo Amós 3.15). Essas esculturas de marfim são semelhantes aos marfins de estilo fenício descobertos em outros lugares, principalmente em Nimrud, localizado hoje no Iraque. Embora a maioria dos marfins tenha sido encontrada em depósitos secundários ou perturbados, com base em comparações tipológicas, eles provavelmente datam do final do século IX a meado do século VIII A.E.C. A presença de itens de luxo de estilo fenício (por exemplo, marfins e vasos de metal) e estatuetas de cerâmica, bem como a aparência generalizada de vasos de cerâmica utilitários, como potes de armazenamento 'torpedo' no interior e no litoral, atestam aos bem-desenvolvidos laços culturais e comerciais entre Israel e a costa fenícia, especialmente com Tiro. (KILLEBREW, 2014, p. 738, tradução nossa; cf. também LION; MICHEL, 2014a; 2014b; SANTOS, 2018).

Em grande curso da evolução estatal está o rei Jeroboam II, talvez o maior rei israelita depois dos dois primeiros reis da dinastia omrida, mas muitas das suas campanhas e realizações mencionadas na Bíblia hebraica requerem mais estudos. Wolfgang Zwickel (2019, p. 286-287) ressalta que “evidentemente, ele conseguiu ampliar o território israelita na região de Basan e talvez incorporar alguns locais no vale de Beqa'". Em relação aos marcantes acontecimentos que se seguem, Zwickel $(2019$, p. 287) afirma que nas campanhas dos anos de 733 e 732 os neoassírios "destroem a hegemonia aramita no Levante" e estabelecem as províncias de Aram-Damasco, Qarnayim e Gilead, sendo que Israel Norte perde novamente seus territórios na Transjordânia. Testemunha histórica, profetas da tradição de Amós ou da "antiga escola de Amós" posicionam-se contrários aos conflitos políticos do seu tempo, possivelmente refletindo sobre a morte do rei Rezin (Radyān) e a queda do reino de Aram-Damasco em 732, dividido em províncias, além do perigo irresolúvel representado pelo império neoassírio que já atinge a Galileia. À luz desses acontecimentos, resta a Israel Norte dez anos como entidade provincial com autonomia na geografia política do sul do Levante.

Em Israel Norte, o agravamento interno dá-se especificamente pelos movimentos contrários à crise econômica, provocada pelas construções e os gastos com as incursões militares em cidades sírias e transjordanianas, empreendimentos iniciados pelo rei Joash (798-783, Yahô'āš ou Yốāš) e mantidos por seu sucessor, Jeroboam II. É possível que Amós, no capítulo 6.13, se refira ao restabelecimento do controle da disputada cidade de Gilead. Os conflitos internos disso decorrentes encontram interlocutores no campo religioso em processo de cristalização de tradições patriarcais. Gilead e Betel fazem parte das bases identitárias israelitas; a essas cidades, Jacob está associado, seja por identidade social (Gilead: Gênesis 31), seja por identidade religiosa (Betel: Gênesis 35.6-8) ${ }^{33}$.

\footnotetext{
${ }^{33}$ Ainda que as textualizações das tradições religiosas que fazem parte de enunciados do período posterior ao exílio babilônio e de diferentes perspectivas, guardam em algumas versões indícios literários do período monárquico; assim podemos citar 1Reis 12.28-29; Amós 7.13; Gênesis 28.10-22; 35.17.
} 
Nesse quadro, o aumento das taxas tributárias gerou a categoria de endividados e forasteiros, sendo alvo dos protestos políticos de um contemporâneo do rei Jeroboam II. Aqui o homem de fé passa a adotar um novo padrão comunicacional entre reis e profetas, distinguindo-se perspectivamente das antigas relações familiais e de servidão ${ }^{34}$. Manteve-se o perfil rústico, do campesino na cidade e entre líderes da cidade: ele é de Teqoa $\left(T e q \bar{o}^{\prime} a\right)^{35}$, é um representante dos pequenos produtores e comerciantes. A arqueologia literária do rolo de Amós lança seu archote sobre um cidadão, boieiro e fruticultor, que lidera o levante dos escasseados na moral contra os tratos de vassalagem impostos pelo império neoassírio e assumidos por seus governantes.

Os escribas ausentaram a voz do rei na textualização, ele foi silenciado e por isso não sabemos o ponto de vista dele, sabemos apenas que o relatório das denúncias foi-lhe encaminhado de Betel (Amós 7.10-11). Em adição, a performance profética ganha singularidade estética no olhar e na voz em termos de literatura compósita do antigo Oriente-Próximo: as circunstâncias acabam por transformar a liderança do homem de fé do setor rural, ele recusa a designação redutora da profecia e se apresenta caracteristicamente como um combatente político em oposição aos modos de governo da monarquia.

\section{Conclusão}

Do que foi abordado até aqui, a atuação do vidente Amós e seus protestos na cidade de Betel, repercutidos em Samaria, capital do reino, ganham em importância para a pesquisa da história quando os enunciados e camadas redacionais do seu rolo ou livro da Bíblia hebraica são situados nos contextos do antigo Oriente-Próximo. Buscamos na operação historiográfica a individuação do agente social, assim como da representação de categoria coletiva, por ele implicada no sistema tributário regulado pela administração real. As duas primeiras partes da pesquisa objetivaram a historiografia dos protestos em favor do pequeno produtor, para cuja validação requereu-nos os sentidos de pertença social de Amós numa análise desapegada da religião, assim como a própria vida do vidente.

Mesmo em meio às dificuldades impostas pela arqueologia literária realizada em literatura de tradições e memórias, repleta de imprecisões textuais e históricas, as descobertas apresentadas destinam-se a servir como introdução de fontes específicas para abordagens da política praticada no

\footnotetext{
${ }^{34}$ Sobre o rei e seu representante oficial, cf. Amós 7; sobre o rei, principalmente 7.10-11.

${ }^{35}$ A palavra Tāqo'‘ $a$ tem a mesma significação de šōpār, "trombeta de corno", "porta-voz". Mapograficamente, a cidade de Teqō'a localizava-se a sudeste de Jerusalém, no reino de Judah.
} 
antigo Israel e seus contatos com as potências imperiais da Antiguidade Oriental na Idade do Ferro.

No quadro político, o domínio neoassírio do mundo no século VIII transformou os modos de vida que ainda mantinham tradições comerciais tribais, vínculos defendidos por líderes do setor rural opositores do regime monárquico, particularmente no sul do Levante. Nesse sentido, as mudanças pelas quais passou o meio ambiente das bordas ou fronteiras testemunham a inexistência de avaliação acerca da implantação dessas novas estruturas mesopotâmias. Com efeito, os testemunhos da materialização de neoassírios $e$ aramitas demonstraram que os conflitos políticos por disputas das cidades fronteiriças não eram impeditivos para as interações culturais, mas interferiam fortemente nas atividades comerciais.

A grande contribuição da coletânea de profecias do Livoro de Amós situase nas questões de política internacional relacionadas com Israel Norte ("Reino do Norte"), sobretudo pelas informações e críticas enunciadas, exatamente por tornar pública uma análise econômica realizada por quem tem conhecimento dos contextos regionais. Ausente inclusive da historiografia deuteronomística dos livros dos Reis (1-2Reis), essa capacidade resultante da ciência dos fatos, que identifica os problemas da economia a partir do conhecimento das estruturas e funções da sociedade em seus devidos contextos históricos, se manteve inédita na Bíblia hebraica.

\section{Referências}

AYALI-DARSHAN, N. The storm-god and the sea: the origin, versions, and diffusion of a myth throughout the ancient Near East. Tübingen: Mohr Siebeck, 2020. (Orientalische Religionen in der Antike, 37).

BERLEJUNG, A. Family ties: constructed memories about Aram and the Aramaeans in the Old Testament. In: OMER, S.; OEMING, M.; HULSTER, I. J. de (Eds.). In search for Aram and Israel: politics, culture, and identity. Tübingen: Mohr Siebeck, 2016. p. 355-377. (Orientalische Religionen in der Antike, 20).

BLUM, E. The relations between Aram and Israel in the $9^{\text {th }}$ and $8^{\text {th }}$ centuries BCE. In: OMER, S.; OEMING, M.; HULSTER, I. J. de (Eds.). In search for Aram and Israel: politics, culture, and identity. Tübingen: Mohr Siebeck, 2016. p. 37-56. (Orientalische Religionen in der Antike, 20).

ELLIGER, K.; RUDOLPH, W. (Hrsg.). Biblia Hebraica Stuttgartensia. Stuttgart: Deutsche Bibelgesellschaft, 1997. 5. aufl.

FINKELSTEIN, I. Israel and Aram: reflections on their border. In: OMER, S.; OEMING, M.; HULSTER, I. J. de (Eds.). In search for Aram and Israel: politics, culture, and identity. Tübingen: Mohr Siebeck, 2016. p. 17-36. (Orientalische Religionen in der Antike, 20). 
GREER, J. S. The cult at Tel Dan: aramean or israelite? In: BERLEJUNG, A.; MAEIR, A. M.; SCHÜLE, A. (Eds.). Wandering aramaeans - Aramaeans outside Syria: textual and archaeological perspectives. Wiesbaden: Harrassowitz Verlag, 2017. p. 3-18. (Leipziger Altorientalistische Studen, 5).

KILLEBREW, A. E. Israel during the Iron Age II period. In: STEINER, M. L.; KILLEBREW, A. E. (Eds.). The Oxford Handbook of the Archaeology of the Levant: c. 8000-332 BCE. Oxford: Oxford University Press, 2014. p. 730-742.

LEMAIRE, A. The boundary between the aramaean kingdom of Damascus and the kingdom of Israel. In: DUŠEK, J.; MYNÁŘOVÁ, J. (Eds.). Aramaean borders: defining aramaean territories in the 10th-8th centuries B.C.E. Leiden; Boston: E. J. Brill, 2019. p. 245-266. (Culture \& History of the Ancient Near East, 101).

LION, B.; MICHEL, C. Le palais et l'entourage royal. In: BORDREUIL, P.; BRIQUEL-CHATONNET, Fr.; MICHEL, C. (Dir.). Les débuts de l'Histoire: civilisations et cultures du Proche-Orient ancien. Nouvelle edition revue et augmentee. Paris: Khéops, 2014a. p. 178-183.

LION, B.; MICHEL, C. Les banquets royaux. In: BORDREUIL, P.; BRIQUELCHATONNET, Fr.; MICHEL, C. (Dir.). Les débuts de l'Histoire: civilisations et cultures du Proche-Orient ancien. Nouvelle edition revue et augmentee. Paris: Khéops, 2014b. p. 187-193.

LIVERANI, M. Para além da Bíblia: história antiga de Israel. São Paulo: Paulus; Loyola, 2008.

MATTHEWS, V. H. The history of Bronze and Iron Age Israel. Oxford: Oxford University Press, 2019.

MIEROOP, M. V. de. Historia del Próximo Oriente antiguo: ca. 3000-323 A.E.C. Madrid: Trotta, 2020.

NISSINEN, M. Ancient prophecy: Near Eastern, biblical, and Greek perspectives. Oxford: Oxford University Press, 2017.

PFEIFFER, H. The origin of YHWH and its attestation. In: OORSCHOT, J. van; WITTE, M. (Eds.). The origins of Yahwism. Berlin: Walter de Gruyter, 2017. p. 115144. (Beihefte zur Zeitschrift für die alttestamentliche Wissenschaft, 484).

ROBERTSON, J. F. Social tensions in the ancient Near East. In: SNELL, D. C. (Ed.). A companion to the ancient Near East. Malden, MA: Blackwell, 2007. p. 212-226.

RUSSELL, S. C. Religious space and structures. In: BARTON, J. (Ed.). The Hebrew Bible: a critical companion. Princeton: Princeton University Press, 2016. p. 356-377.

SANTOS, J. B. R. Elementos de direito político-econômico e as estruturas de poder no antigo Israel. Caminhando, São Bernardo do Campo, v. 14, n. 2, p. 155-170, 2009.

SANTOS, J. B. R. Contra o etnocídio do profeta 'Ēliyyāhû, o tišəbî: conflito e apropriação de lugar sagrado em um pequeno reino do Levante. Estudo de fonte hebraica. Oficina do Historiador, Porto Alegre, v. 10, n. 2, p. 131-147, 2017.

SANTOS, J. B. R. Dos conflitos com 'Ārām ao deus de Ha-la-ab: a formação do campo religioso e a elaboração do Yhwh no Yiśrā'ēl Norte na Idade do Ferro II. 2018. Tese (Doutorado em Ciências da Religião) - Universidade Metodista de São Paulo, São Bernardo do Campo, 2018. 
SANTOS, J. B. R. O monumento do rei Meša' de Mū'aba: o liame dos fatos envolvendo moabitas e israelitas do norte na Idade do Ferro II. Phoînix, Rio de Janeiro, v. 25, n. 2, p. 11-25, 2019a.

SANTOS, J. B. R. Para além de Tēl Dān: os contextos e conexões dos conflitos entre aramitas e israelitas na Idade do Ferro II. Classica - Revista Brasileira de Estudos Clássicos, São Paulo, v. 32, n. 2, p. 91-114, 2019 b.

SANTOS, J. B. R. "Grandes olhos negros": o ícone literário da princesa fenícia 'Îzebel na corte israelita do século IX A.E.C. nos contextos das linguagens culturais levantinas. Estudos de Religião, São Bernardo do Campo, v. 33, n. 3, p. 257-274, 2019c.

SANTOS, J. B. R. O relevo do fato e da fala: Israel Norte no “Obelisco Negro" de Shalmaneser III e seus contextos na Idade do Ferro II. História (São Paulo), Assis/ Franca, 2021. [Em edição para publicação em 2021].

WAZANA, N. Amos against Amaziah (Amos 7:10-17): a case of mutual exclusion. Vetus Testamentum, Leiden, v. 70, n. 1, p. 209-228, 2020.

WEINGART, K. 2 Kings 15-18: a chronological conundrum?. In: HASEGAWA, S.; LEVIN, C.; RADNER, K. (Eds.). The last days of the kingdom of Israel. Berlin: Walter de Gruyter, 2020. p. 267-288.

YOUNGER, K. L. A political history of the arameans: from their origins to the end of their polities. Atlanta, GA: SBL Press, 2016.

ZWICKEL, W. Borders between Aram-Damascus and Israel: a historical investigation. In: DUŠEK, J.; MYNÁŘOVÁ, J. (Eds.). Aramaean borders: defining aramaean territories in the $10^{\text {th }}-8^{\text {th }}$ centuries B.C.E. Leiden; Boston: E. J. Brill, 2019. p. 267-335. (Culture \& History of the Ancient Near East, 101).

Artigo submetido em 14.11.2020 e aprovado em 21.06.2021.

João Batista Ribeiro Santos é Doutor em Ciências da Religião (Ph. D. in Religious Studies pela Universidade Metodista de São Paulo (ECEH/UMESP), Pós-Doutor em História Antiga (Postdoctoral in Ancient History) pela Faculdade de Ciências e Letras da Universidade Estadual Paulista (FCL/UNESP), docente e editor da Escola de Teologia da Universidade Metodista de São Paulo (UMESP). Orcid.org/0000-0002-9087-3061. E-mail: joao.ribeiro@metodista.br

Endereço: Rua do Sacramento, 458 - Casa 2 - Rudge Ramos 09640-000 São Bernardo do Campo - SP 